\title{
Preface: Why Do Emotions History?
}

\author{
Peter N. STEarns \\ Provost Emeritus and University Professor \\ George Mason University \\ Department of History and Art History
}

Expansion of the field of emotions history to include greater participation by Spanish scholars and greater attention to applications of the approach to Spanish history -which this volume reflects and promotes- is a truly welcome development. It's clear that one of the several signs of success in this vibrant subfield is extending the geographical range, and Spain is emerging as a key case in point. I welcome the invitation to contribute a few comments about the field by way of introduction.

The overall growth of what some are calling the "emotional turn" in the history discipline is obvious, and probably the main outlines are becoming fairly familiar. The field began, in any explicit sense, with Lucien Febvre's call for attention to the "whole physical, intellectual and moral universe of past generations", emotions most definitely included. Febvre himself did not explore this option directly, though elements show through in his magisterial work on the Problem of Unbelief. It was only considerably later that several French scholars broadly speaking in the Annales tradition began to probe past emotions directly, as in Jean Delumeau's several studies of fear across a broad chronological range. Some attention to emotional facets became part of the interest in mentalités. Meanwhile, on the other side of the Atlantic (though with some boosts as well from British researchers) the growing interest in family history began to spill into the emotions area. And the field was up and running ${ }^{1}$.

It is worth remembering that both these points of origin (post-Febvre, particularly) had to clear away some countercurrents, and of course this process is ongoing. First, a huge disciplinary tradition urged primary focus on political history, usually defined in terms of rational actors and the careful plotting of policy and strategy. Diplomatic history, as an example, came straight from the archives of statesmen who prided themselves on their sober judgments. Emotions need not apply, except perhaps as echoes of nationalistic crowd noises intruded on the deliberations (as in discussions of the origins of World War I). Then, when social historians began to contest the terrain, urging options in addition to political history, they too initially insisted on a rational actor approach. In the 1960s one of the key lessons from Anglo-American social history was that crowds behaved quite rationally, as against the conservative attacks of earlier social psychologists like Gustave Le Bon. Crowds chose targets deliberately in relation to clear goals, and they were not diverted by emotion. The desire to skirt emotion even informed much of the early work on family history. Families were studied, as in the excellent work of the Cambridge group, in terms of demography, household

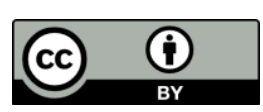

1. Lucien Febvre, The Problem of Unbelief in the 16th Century: The Religion of Rabelais, Cambridge, Harvard University Press, 1985, 9 and passim; Jean DELUMEAU, Sin and Fear: The Emergence of the Western Guilt Culture, 13Th-18th Centuries, New York, Palgrave Macmillan, 1990; John DEMOS, A Little Commonwealth: Family Life in Plymouth Colony, Oxford, UK, Oxford University Press, 1999; Lawrence STONE, Family, Sex and Marriage in England 1500-1800, New York, Harper Perennial, 1983. 
composition, and other measures many of which were resolutely quantitative, helping to justify social history's early claim to be part of a social science package.

Why did this situation change, allowing the first clear forays into emotions history? I don't think we have a full explanation yet, but some factors clearly deserve consideration.

In the first place, the very interests of the so-called new social historians made it hard to stay away from emotions permanently. This is abundantly clear in the case of family history. Only so much attention to quantitative data was possible without asking about the emotional factors involved. For example, important work highlighted the demographic transition of the late $19^{\text {th }}$ century in the West, with rapidly declining birth and infant death rates. But why did this occur? Were there emotional elements involved in decisions to have fewer children? Were there emotional consequences of lower death rates? The answers, as even resolute demographers discovered, were clearly yes, and yes -and one aspect of the history of emotions was actively underway.

The social sciences themselves were changing. Psychologists had long studied emotion, and they still rule the roost in terms of sheer volume of research. But awareness of some of the findings of social psychology began to creep into sociology and anthropology. Sociologists for example began writing about the emotional costs of modern work organization. Anthropologists studied differences in the emotional configurations, even sometimes the basic emotional vocabulary, of diverse societies. Even a few social psychologists ventured outside standard territory to wonder about change over time ${ }^{2}$. Not surprisingly, some of these expanding interests came to the attention of some historians, almost deliberately inviting a clearer historical contribution to an expanding interdisciplinary dialogue about emotion. Emotions were becoming a hot topic in a number of fields, and this development spilled over. When the International Society for Research on Emotion was formed, in 1984, its first invited keynote speaker was a historian.

Within this context, it turned out that there were several existing theories that cried out for further historical utilization and testing. Most obviously, interest in the civilizing process idea of Norbert Elias, calling attention to changes in emotional and bodily standards and the role of manners as regulators, gained new prominence. This was, again, an interdisciplinary dialogue, with Dutch and German sociologists taking an active role along with historians ${ }^{3}$. And the result was not only additional work but also heated debate -a clear sign the field was taking hold in a chronically contentious discipline. Medievalists, most obviously, objected to the idea that their era had been emotionally unregulated, and contention over the nature of change added spice and focus to emotions history ${ }^{4}$.

2. Arlie HochsCHILD, The Managed Heart: Commercialization of Human Feeling, Berkeley, University of California Press, 2012; Robert LEVy, Tahitians: Mind and Experience in the Society Islands, Chicago, University Of Chicago Press, 1975; Stephanie SHIELDS, Speaking from the Heart: Gender and the Social Meaning of Emotion (Studies in Emotion and Social Interaction), Cambridge, UK, Cambridge University Press, 2010.

3. Cas Wouters, Informalization: Manners and Emotions Since 1890, London, SAGE, 2007; Cas WOUTERS, Sex and Manners: Female Emancipation in the West 1890 - 2000, London, SAGE, 2004).

4. Barbara Rosenwein, Emotional Communities in the Early Middle Ages, Ithaca, Cornell University Press, 2007. 
More broadly still - and this is a question, not a statement of fact - was something going on in the wider society that encouraged this new attention to emotion, this move away from rational actor approaches to the past? Certainly, back in the early 1940s, a powerful influence on Febvre's appeal for emotions history was his acute awareness of the power of emotion in the Nazi movement that had come to engulf France by war. Motivations and even political actions - perhaps, particularly political actions - simply could not be grasped without actively including an emotional element. Was this same broader realization gaining new traction in the post-1960s atmosphere of the West? As Marxism declined, and feminism gained ground (with, I hasten to add, a very complex relationship to stereotypes about women and emotion), was there a wider context that encouraged the overall expansion of emotions research and that drew historians in as well?

Certainly, once emotions history got going, with only a fairly brief gestation period, it began to gain surprising momentum. Work labeled as emotions history expanded in volume. Institutional support emerged, most notably with important study centers in Berlin (Max Planck), the UK (Queen Mary center) and most impressively in terms of funding, Australia with Centre of Excellence based in Perth. And of course there was geographical expansion as well, as a field initially firmly but narrowly anchored in the Western experience began to branch out. Important work emerged on Eastern Europe and China ${ }^{5}$, and this aspect of growth continues -as this volume abundantly illustrates.

Ultimately, we need to figure out why this unexpected success occurred, beyond what the initial causes of emotions history would have allowed us to predict. Further interdisciplinary and possibly popular interest in emotion is surely one angle. Opportunities for cross-disciplinary work in the humanities - not initially a major thrustconstitutes another. A good bit of the growth of emotions history has involved the occasions it presents to art historians, literature and theater buffs and other to link their work with one of the popular intellectual menu items of the day. At a time when in many respects the humanities are under siege because of their distance from practical concerns, emotions work may seem to be a bit of a refuge, providing a new set of reasons to offer humanities wares. And of course, by this point, there is the excitement of real discovery. On various fronts, historians were producing new information and analysis about how emotions operated in the past. We learn, to take just one example among many, how different (and powerful) nostalgia was in Western culture two centuries ago to what we experience today, but also how a milder form of nostalgia powerfully informs the decisions many Americans make about family life and domestic consumerism ${ }^{6}$. Advances like this clearly and properly encourage additional work.

Amid the expansion, and in hopes of still more to come as in the expansion of interest in Spain, one basic question deserves emphasis, for it can get lost in the growing excitement. What are the fundamental purposes of emotions history? As more and more scholars participate in emotions history, we need as clear as possible an overall rationale, beyond the inevitable scattering of specific projects. What should we, and what should our audiences, expect to gain from history's emotional turn? What

5. See the essays in Susan MatT and Peter Stearns (eds.), Doing Emotions History, Champaign (IL), University of Illinois Press, 2014.

6. Susan MATt, Homesickness: An American History, New York, Oxford University Press, 2011). 
overarching goals should scholars keep in mind as they plumb the growing variety of monographic topics?

We begin with two basic premises, that were part of Febvre's thinking when he called for a history of emotion. The first is fundamental to emotions study of any sort, the second, a bit more contestable, pertains to history specifically.

1. Human beings must be studied in their full range -"physical, intellectual, moral"-, and emotions are central here. Emotions form basic elements in motivation, expression, impact, and they must be included in historical research.

2. Emotions can change over time in themselves, and certainly in their social definition and role. Febvre insisted that human nature is not always the same, and historians of emotion maintain this commitment to exploring change as part of their historical projects and as their key contribution to understanding emotions more generally.

If these assumptions are granted, then, two results follow fairly obviously. First, historians of emotion believe that their focus will help us better understand the past, or key episodes in the past, whether the subject is experience of war or the exploration of health and disease. I think we should commit to being as explicit about this as possible to indicate clearly how the emotions component improves our grasp -so that we can model this aspect for other researchers.

But second, we should also - not always, but with some preference- chose passages in the past where some degree of change might be involved. This is, I truly believe, our disciplinary edge in the field, and I do worry that we are not following through consistently enough amid the delight in finding very specific past moments to explore. I do not at all mean that every project should involve changes in emotions and emotional standards, or emotional reactions to change, but I do think the opportunity should remain front and center.

Is there also a third purpose, shading off particularly from the exploration of change: can historians aspire also to improve our understanding of emotions themselves? If we are right that emotions not only constitute a vital facet of humanity, but also that emotions change, then we do have some claim to participate in interdisciplinary discussions of what emotions are all about.

Let me offer a specific example. Emotions historians of the United States have pretty good reason to believe that an emphasis on shame began to decline in this society from the early $19^{\text {th }}$ century onward, and recent content analysis probes confirm this. And we can come up with some highly plausible causes for this important shift. It's a shift that other scholars who work on shame -whether social psychologists who widely agree that shame is an unproductive or even destructive emotion, or anthropologists who compare other societies where shame looms larger- should know about. For analysis of the downsides of contemporary shame must come to grips with the implications of the larger change over time. For the change may have reduced the problem that shame poses without, clearly, eliminating it; or it may have made the shame that does remain more difficult to manage, because it now seems so inappropriate, even unfair. History, here, enters directly into a larger assessment ${ }^{7}$.

7. Peter Stearns, "Shame and a Challenge for Emotions History" (presentation, American Historical Association, New York, NY, January 2-5, 2015). 
Potentially, then, the purposes of emotions history are genuinely ambitious. We use emotions explicitly to improve our grasp of the past, including aspects that must be understood in other-than-contemporary emotional terms. We work on change, adding this element to the overall framework for the subject. And we engage, at points, on what emotions themselves are all about, particularly when we move from past trends to current debates.

Insistence on core purposes, finally, leads to the question of audience, where emotions historians also need to be as explicit as possible. Obviously, we write for other historians and in some cases now also for a wider range of humanists. The expansion of emotions history has made this internal audience increasingly prominent. And many emotions historians also want to address colleagues who do not identify themselves in the emotions field, but whose own work -again, whether it's World War I, or the Renaissance, or late- $19^{\text {th }}$-century health- will be improved if they can fold in relevant emotions findings. Again, however, without slighting these targets, it is possible to urge two others as well. One, occasionally at least, might be that elusive animal, the general reading public. Properly done and energetically presented, the best work in emotions history may merit a wide readership, precisely because it explores subjects that connect directly to general experience. This is an occasional and difficult frontier, I admit, but we should not forget it. At least as important, and in principle considerably more accessible, is an interdisciplinary scholarly audience that will directly embrace the other fields commonly associated with emotions research: psychology, sociology and anthropology, philosophy, and now neuroscience. This is where the contributions to the emotions field will particularly pay off, and we must embrace the opportunity, at least occasionally, even though it is less familiar.

Emotions history is hard work, as the participants in this volume can surely attest. It involves some issues that are difficult to resolve, and that may never be resolved fully. Sources are not always easy to come by, which is surely one reason a wide range of cultural materials are coming into play. It is notoriously hard to move from awareness of emotional standards -which societies generate fairly routinely, at least for some emotions - to actual emotional experience, though the social use of standards is an interesting way-station in and of itself. Tensions around "basic" emotions -how much do we need to know about bio-psychological constants, versus cultural variables- add an important component. Social class is a vital factor, and again it poses difficulties: it is so much easier to deal with "articulate" social groups who leave records about their emotional lives and for whom prescriptive literature is often particularly directed. And of course, at least for the moment, there remains a geography issue, as we know more about emotions history in some regions than in others, a fact that also constrains our capacity to compare ${ }^{8}$.

These are challenges that will surely lead to greater sophistication and at least fuller if not complete resolution, as the field continues to expand. But the main point is that the challenges are worth working on. Emotions historians have a line of vision that will expand the usable past and improve our evaluations of it. And, at points at least, they add as well to basic knowledge about emotions themselves.

8. MatT \& Stearns, Doing Emotions History. 